\section{Projeto Bambuí: a experiência do cuidado domiciliário por esposas de idosos dependentes}

\author{
The Bambui Health and Aging Study (BHAS): \\ the experience with home care provided \\ by wives of dependent elderly
}

\author{
1 Programa de Pós-graduação \\ em Saúde Pública, \\ Universidade Federal \\ de Minas Gerais, \\ Belo Horizonte, Brasil. \\ 2 Núcleo de Estudos \\ em Saúde Pública \\ e Envelhecimento, \\ Centro de Pesquisas René \\ Rachou, Fundação Oswaldo \\ Cruz/Faculdade de Medicina \\ Universidade Federal \\ de Minas Gerais, \\ Belo Horizonte, Brasil. \\ Correspondência \\ K. C. Giacomin \\ Núcleo de Estudos em Saúde \\ Pública e Envelhecimento, \\ Centro de Pesquisas René \\ Rachou, Fundação Oswaldo \\ Cruz, Faculdade de \\ Medicina, Universidade \\ Federal de Minas Gerais. \\ Av. Augusto de Lima 1715, \\ Belo Horizonte, $M G$ \\ 30190-002, Brasil. \\ giacomin@cpqrr.fiocruz.br
}

\begin{abstract}
This paper investigates the characteristics of caregiving and the experience of women that care for their elderly husbands in Bambui, Minas Gerais, Brazil. Among the elderly population in this community, the authors interviewed ten wives, using a survey exploring the main themes on the subject of caregiving. The data were interpreted based on an anthropological model of analysis. This model places the interaction between the individual and the context in the center of the interpretative process, underlying the construction and expression of diverse forms of human experience. The results of the survey highlighted the role, responsibilities, and obligations of women in Brazilian society with respect to caregiving for dependent elders. Women are seen as "natural" caregivers, whereby it is their given obligation to take care of their husbands, providing all kinds of support. Both the individual in need of care and the caregiver live the reality of functional disability in a society lacking the proper mechanisms to provide for the elderly population. The current study clearly shows the need to systematize home caregiving in Brazilian society.
\end{abstract}

Anthropology; Aged; Caregivers
Karla C. Giacomin 1,2

Elizabeth Uchoa 2

Maria Fernanda F. Lima-Costa ${ }^{2}$

\section{Introdução}

O envelhecimento populacional brasileiro tem sido muito rápido e intenso. A cada ano, $650 \mathrm{mil}$ idosos são incorporados à população brasileira 1. O cuidado de uma população que envelhece representa um extraordinário desafio, especialmente pelo crescimento ainda mais acelerado da parcela idosa frágil e muito idosa da população 1,2 e por esse grupo apresentar uma grande carga de doenças crônicas e incapacitantes, quando comparado a outros grupos etários 3,4,5. Disso resulta uma demanda crescente por serviços sociais e de saúde 6 , mas é a família a instituição que cumpre o papel social de cuidar de idosos frágeis 5,7,8. Apesar de relevantes estudos terem apontado a realidade de desigualdade social e de saúde entre os idosos brasileiros $3,4,9,10,11$, ainda não existem políticas oficiais direcionadas para o cuidado à população idosa que desenvolve dependência funcional e não há o reconhecimento dos cuidadores de idosos nessa atenção cotidiana.

Entende-se a saúde do idoso como a interação multidimensional entre saúde física, mental, independência na vida diária, integração social, suporte familiar e independência econômica 7. A capacidade funcional é um indicador de saúde dos idosos e a incapacidade funcional, um sinal de falência da habilidade em realizar as atividades cotidianas, seja pela presença de déficits físicos 12,13 ou cognitivos 13,14, 
seja, mesmo, pelo processo contínuo do envelhecimento ${ }^{15}$. A dependência é a expressão da dificuldade ou incapacidade em realizar uma atividade específica por causa de um problema de saúde 16. A existência de uma incapacidade funcional determina a necessidade de um cuidador 17 .

Cuidador é a pessoa que oferece cuidados para suprir a incapacidade funcional, temporária ou definitiva. O cuidador pode ser informal ou formal. A figura do cuidador já é assimilada, nos países desenvolvidos, como um parceiro da equipe de saúde, mas isto não acontece no Brasil. Na Inglaterra, estima-se que mais de seis milhões de pessoas sejam cuidadoras de pessoas dependentes, em sua maioria idosos 18 .

Dados da Pesquisa Nacional de Amostra de Domicílios (PNAD 1998) 11, conduzida em uma amostra representativa da população idosa brasileira (exceto região Norte), mostram que $13,9 \%$ dos idosos tiveram suas atividades rotineiras interrompidas por problemas de saúde nas duas semanas anteriores à entrevista 4 . Essa necessidade de cuidado não vem sendo considerada, de maneira explícita, pelo sistema de saúde brasileiro.

Nos países desenvolvidos, o cuidado formal, que é oferecido pelo sistema de saúde 19, vem superpor-se ao cuidado informal oferecido por familiares; no Brasil, o cuidado formal, organizado e eficiente para idosos dependentes praticamente nunca existiu. O cuidado do idoso dependente sempre coube à família brasileira. Inexistem estruturas intermediárias de cuidado entre a família e a instituição de longa permanência para idosos. Estruturas de suporte como centros-dia, hospitais-dia, visitas regulares de enfermeiros, embora previstos em lei 20, ainda não estão disponíveis para a grande maioria da população idosa brasileira. Os idosos frágeis, acamados e seus cuidadores familiares apenas recentemente têm sido visitados pelo sistema de saúde, por intermédio do Programa Saúde da Família (PSF). O Sistema Único de Saúde (SUS) ainda não garante esse cuidado domiciliário de longa permanência.

Os cuidadores de idosos experimentam um fardo considerável e estão em maior risco de morbidade psiquiátrica e física comparados à população geral e a grupos 21,22. Estudos brasileiros sobre cuidadores de idosos têm discutido questões psicológicas e sociais com base em grupos selecionados de cuidadores 17,23,24,25.

Um estudo epidemiológico realizado entre idosos residentes na comunidade de Bambuí, Minas Gerais, Brasil, revelou a magnitude do problema: $23,0 \%$ dos idosos necessitavam de cuidador 26 . Todavia, não se conhecem as exi- gências concretas ditadas pelo cuidado a um idoso dependente no seu domicílio, nem a experiência vivida pelo cuidador. São necessárias investigações mais profundas sobre os elementos que influenciam as percepções e ações de quem cuida.

O presente trabalho, desenvolvido como parte do Projeto Bambuí, tem por objetivo explorar, fundamentando-se numa visão antropológica, a conjugação entre elementos externos e internos na determinação das exigências e significados inerentes ao cuidado e na construção das experiências de esposas que cuidam de homens idosos numa cidade do interior do Brasil.

\section{Uma abordagem antropológica do cuidado}

Dentro da perspectiva antropológica, o envelhecimento é encarado como um fenômeno universal que gera problemas comuns, mas que podem ser vividos e resolvidos diferentemente pelas culturas 27 . Considera-se o envelhecimento como um fenômeno biológico ao qual o indivíduo reage com base em suas referências pessoais e culturais 28 . O processo biológico é, assim, apropriado e elaborado simbolicamente, ao longo da vida, por rituais que definem um sentido político e organizador do sistema social 29. Nesta perspectiva, representações e práticas em relação ao indivíduo que envelhece devem ser compreendidas como elementos do universo de regras sociais e símbolos culturais que as guiam e as validam. O estudo da experiência do cuidar de um idoso deve ser explorado em referência a um universo social e cultural específico.

A corrente interpretativa da antropologia desenvolveu conceitos essenciais para avançar nessa direção. Geertz 30 define a cultura como um universo de símbolos e significados que permite aos indivíduos de um grupo interpretar a experiência e guiar suas ações e afirma que a cultura forneceria "modelos de" e "modelos para" construção de realidades sociais e psicológicas participando, então, da construção de todo fenômeno humano. As emoções, percepções e ações dos indivíduos são construídas em referência a um universo cultural de significados que lhes permite interpretar e responder aos diferentes acontecimentos e situações da vida 8,31 . Tal perspectiva coloca a interação entre o indivíduo e o contexto no centro do processo interpretativo que subentende a construção e a expressão de diversas formas de experiência humana 31,32 . No presente estudo, a narrativa de cada cuidadora será analisada com o 
objetivo de compreender como a experiência de cuidar (percepções, emoções e ações) é construída no interior de uma história de vida e na interação com um contexto social e cultural específico 31,33 . A investigação terá como eixos fundamentais: os elementos internos (as necessidades e exigências ditadas pelo cuidado, as características pessoais de quem é cuidado e as do cuidador) e externos (dos contextos social, cultural e político) que constroem o cuidado.

Serão focalizadas características do processo de cuidar: O que é esse cuidado? Quem são essas cuidadoras? O que elas fazem? Como percebem o cuidado em suas vidas? O que desejam? Com quem podem contar? Por que estão cuidando? Quais significados são atribuídos às suas experiências de cuidado (emoções positivas e negativas, situações de estresse e apontamento de possíveis estratégias facilitadoras do cuidado)?

\section{População estudada}

Este estudo foi realizado com esposas que cuidam de seus maridos idosos participantes do Projeto Bambuí, um estudo de coorte com base populacional de idosos residentes na comunidade. O Projeto Bambuí iniciou-se com o recenseamento da população idosa residente no Município ( $\mathrm{n}=1.742)$ e com a realização de entrevistas e exames na linha de base constituída em 1997, que contou com a participação de $92,0 \%$ de toda a população com sessenta e mais anos de idade $(n=1.606)$. As entrevistas anuais de seguimento foram iniciadas em 1997 e continuarão até 2007. Uma descrição detalhada do Projeto Bambuí pode ser encontrada em Lima-Costa et al. ${ }^{34}$.

Em um estudo epidemiológico anterior 26, investigou-se qual era a necessidade de cuidador entre os idosos participantes da linha de base do Projeto Bambuí (1997). Foram identificados 370 (23,0\%) idosos que necessitavam de cuidador, sendo 146 homens e 224 mulheres. $\mathrm{Na}$ entrevista de seguimento do ano 2003, 11 homens disseram ser cuidados por suas esposas e foram selecionados. Todos foram procurados. Um deles havia mudado de Bambuí. Os outros dez homens foram localizados e suas esposas foram convidadas a participar do estudo. Todas aceitaram.

\section{Coleta e análise de dados}

As entrevistas foram realizadas no Posto de Saúde Emmanuel Dias da Fundação Oswaldo Cruz, em Bambuí. Todas as entrevistas foram realizadas por uma das pesquisadoras (K. C. G.), com o consentimento das participantes, após esclarecimento.

Foi utilizado um roteiro de questões com os temas sugeridos pela literatura (quem é a pessoa de quem ela cuida, qual a doença, há quanto tempo, as percepções individuais dos papéis e tarefas do cuidador, os sentimentos experimentados, o significado do cuidado, cuidado e solidão, cuidado e solidariedade, a presença de outras pessoas e de serviços institucionais que auxiliavam no cuidado, o impacto de estar cuidando) 19,35,36,37,38,39,40,41,42.

\section{Análise}

Todas as entrevistas foram gravadas e transcritas. Após a leitura atenta das mesmas, foram criadas categorias analíticas que permitissem fragmentar a totalidade das entrevistas nos grandes eixos temáticos mencionados 31,32,43,44. Uma primeira análise de conteúdo da informação assim codificada permitiu a identificação de categorias analíticas mais finas (subcategorias) e, posteriormente, a verificação das ocorrências de cada categoria analítica e extração dos textos correspondentes a uma ou mais dessas categorias. A análise de conteúdo focalizou, primeiramente, 16 categorias, que versavam sobre: (a) o cuidado propriamente dito (início da doença do marido, tipo de cuidado realizado, necessidades, dificuldades e razões evocadas para o cuidado); (b) as estratégias desenvolvidas para cuidar e as mudanças determinadas pelo cuidado na vida do cuidador, incluindo a administração do tempo livre e o papel da religião; (c) o contexto social em que se dá o cuidado: ajuda institucional, ajuda de outros, recursos financeiros (seguridade social, rendimentos, trabalho na juventude); (d) as dificuldades em expressar descontentamento e as contradições do discurso das cuidadoras. Em um segundo momento, focalizou-se a interação entre essas categorias e sua articulação com o contexto sócio-cultural vigente.

\section{A experiência e o significado do cuidado}

As esposas entrevistadas são donas de casa, têm idades entre 57 e 90 anos e estudaram no máximo até o quarto ano do ensino fundamental. Todas residem na cidade de Bambuí e vivem com o marido em casas próprias. Quando jovens, elas exerceram profissões braçais e pouco qualificadas (empregada doméstica, lava- 
deira, lavradora), na zona rural ou na cidade. Todas, com apenas uma exceção, têm renda mensal familiar de até dois salários mínimos, e cinco delas não possuem qualquer rendimento ou benefício de seguridade e as demais recebem mensalmente um salário mínimo - quatro por aposentadoria (Instituto Nacional de Seguridade Social - INSS) e uma por invalidez temporária. A maioria gerencia o dinheiro do casal, mas apenas uma é legalmente curadora do marido.

Todas as entrevistadas referem-se à necessidade de cuidar do marido de forma integral, isto é, elas devem ser uma presença constante e ter a disponibilidade para ajudá-lo em quase todas as tarefas cotidianas, ao longo de todo o dia. Uma delas compara as necessidades do marido àquelas de uma criança e explica: "ele é que nem uma criança, eu dou banho nele, a comida eu ponho no prato pra ele, o remédio eu dou na mão, senão eu ponho até na boca, $e$ água também" (Entrevistada 8, 67 anos). Outra entrevistada enfatiza as exigências ao longo de todo dia: "de manhã, tenho que dar a ele o café, tudo 'arrumadinho', pôr na mão, lá pra ele. Sou eu quem dá o banho nele. Ajudo ele a deitar. Pra dormir, dou a ele o pijama, facilito pra ele vestir. Eu o ajudo" (Entrevistada 10, 90 anos).

Na descrição das tarefas que constituem o cuidado integral, incluem-se aquelas relacionadas ao cuidado do corpo (higiene, vestuário, banho), as domésticas (cuidado da casa e da alimentação), a necessidade de presença física em tempo integral e os cuidados referentes a tratamentos de saúde (ida ao médico, administração de medicamentos). Geralmente, as esposas consideram as tarefas que exigem maior intimidade, como o banho, a higiene íntima e o cuidado de feridas, como as mais difíceis de serem realizadas: "eu acho mais difícil na hora do banho, na hora dele ir à instalação também eu acho difícil porque ele não vai sozinho. Ele escorrega, cai e vira aquela confusão" (Entrevistada 1, 72 anos). Há também relato de uma progressão das necessidades com a evolução da doença. Uma das cuidadoras descreve em detalhes o processo: "porque, com esse braço assim, eu levantava ele, eu escorava ele, punha uns travesseiros, ele sentava e comia. Agora não. [Ele tem de comer deitado]. Isso aqui nele virou dó [aponta a região lombar], ficou na carne viva, a cama ficava toda molhada. Precisa lavar a roupa todo dia. Soltava uma água mal cheirosa, ruim, sabe?" (Entrevistada 3, 73 anos).

O comportamento do marido, atual ou passado, parece complicar a situação: agressivo, pirracento, custoso, luxento, "descompreendido", teimoso, impertinente são alguns dos ad- jetivos escolhidos pelas mulheres para falar de seus esposos. Uma delas explica: "ele é daquelas pessoas que é igual menino, menino a gente pega e leva. Ele não. Se ele falar: 'não'. É desse jeito... Quanto mais fala, pior fica" (Entrevistada 5, 74 anos). Três mulheres evocaram relacionamentos extraconjugais de seus maridos. Uma senhora argumenta: "tem que brincar. (...) Tem dia que eu enfezo lá eu falo: 'cadê a fulana agora, né? Agora que era hora dela ajudar. (...) Quantas vezes você me largou aqui sem os trem dos meninos e foi cuidar dela, né? Passear? Ia passear, né?' Difícil demais a vida" (Entrevistada 4, 73 anos). A resignação é, na maioria das vezes utilizada, para facilitar o exercício do papel de cuidadora.

A violência doméstica também aparece em dois relatos: "é uma vez, é tem duas vezes que eu apanhei dele, que eu apanhei pra valer, isso foi no começo. Ele não bebia. Ele nunca bebeu. Bateu em mim, uma vez foi por conta de, nós estávamos fazendo um banheiro (...) e outra vez foi lá na roça, nós não tínhamos família ainda não" (Entrevistada 8, 67 anos). Ela afirma ter passado fome com os filhos ainda pequenos: "eu bati nela [na filha pequena]. Eu não queria que meu irmão soubesse que eu não tinha nada de comer, e no fundo morava uma vizinha, no meu lote, também eu não queria que ela ouvisse ela gritar que tava com fome, não" (Entrevistada 8,67 anos). A outra mulher diz: "quando ele tá nervoso, ele fala que eu não faço nada, que eu vivo à toa [risos]. Deus me livre, sá, é duro!" (Entrevistada 4,73 anos).

Apesar das inúmeras atividades incluídas pelas cuidadoras na prestação desse cuidado integral, apenas três delas foram capazes de situar, no tempo, o momento em que se tornaram cuidadoras de seus maridos e, somente uma, informou a data precisa de início: “dia 10 de abril, faz dezesseis anos. A doença dele, nós falamos derrame (...) e ele tem glicose alta, pressão alta" (Entrevistada 5, 74 anos). Duas entrevistadas confundem o início do cuidado com o início do próprio casamento. Uma delas explica: " toda vida eu cuidei dele, mas na saúde, porque a gente é obrigada, né? Eu sempre colocava [comida no prato], mas é por amizade, sabe? Mas não é assim de precisão não. Agora que é de precisão" (Entrevistada 1, 72 anos).

Parece que a dificuldade de precisar o momento em que se tornaram cuidadoras pode ser, em parte, explicada pela semelhança entre as tarefas que realizam ao cuidar do marido e as tarefas domésticas que elas sempre realizaram como esposas. O cuidado com a casa, com a roupa e com a alimentação faz parte das atribuições da esposa desde o início do casamento 
e não é percebido como um fardo. As novas atribuições relacionadas à higiene íntima e ao cuidado com feridas são recentes e exigem maior intimidade com o esposo, talvez, por essas razões, sejam consideradas as mais difíceis. A higiene íntima envolve o pudor de ambos, traz à tona dificuldades conjugais e evoca a decadência do corpo e do próprio casal - que não existe mais para o prazer. As tarefas de cuidado com o corpo do marido refletem um envelhecimento mal sucedido e um futuro projetado das próprias mulheres idosas. Além disso, elas supõem a aprendizagem de novas habilidades (inclusive físicas - de acomodar, mudar de posição e/ou carregar o marido; e psicológicas de estímulo, escuta). Ainda assim, as entrevistadas acolhem essas novas tarefas como esposas. Ao se casar, elas assumiram o compromisso de cuidar do marido na saúde e na doença. Essa verdade a mulher assimila sem questionar, sem pedir ou aceitar ajuda.

A ajuda de outras pessoas incluindo os filhos, parentes e vizinhos, embora relatada pela maioria das cuidadoras, não acontece de fato. Quase todas justificam a impossibilidade dos(as) filhos(as) em participar do cuidado, por distintas razões: problemas de saúde dos filhos, falta de tempo, dificuldade financeira, trabalho, imposição da pessoa que é cuidada. Uma senhora fala de seu desamparo, mas reafirma que os filhos não são maus: " $a$ h, tem hora que eu sinto [desamparo]. Que os meus filho são muito bons, não estou falando que eles são ruins, não. Mas acho que o povo hoje em dia, os mais novos, não querem saber de gente idoso, eles não acham que a gente precisa deles" (Entrevistada 8, 67 anos). Uma outra senhora explica que a realidade é inversa: "eu fico dando apoio, invés delas me darem, eu que dou. Mas a gente que é mais antiga, boba, conheceu muito o mundo pra trás" (Entrevistada 5, 74 anos). Apenas uma esposa reclama : "não é dizer que eu preciso não, que meus filhos me ajudam, mas eles não dão à gente nada, nem a cesta [básica de alimentos]. Ele devia de ganhar uma cesta porque eu só não dou conta. O dinheiro dele vai pro remédio e pro médico" (Entrevistada 10, 90 anos).

Nos poucos casos em que outros participam do cuidado, a ajuda é sempre dada por outras mulheres: "ah, depois ele veio pra casa, minhas meninas cuidavam, minha cunhada cuidava, minha nora que mora lá na porta da cozinha é que lavava roupa, fazia a comida" (Entrevistada 3, 73 anos).

Para cumprir com as exigências do cuidado ao marido, duas entrevistadas precisaram modificar o domicílio, entretanto o fizeram sem orientação profissional. Uma delas explica “eu suspendi os dois quartos, pra eu dar conta de subir ele sozinha, e tirar ele do quarto sozinha, porque chamar [alguém] diário não tem jeito. (...) Aí ele ficou pior, porque levou um tombo lá" (Entrevistada 5, 74 anos).

Quatro entrevistadas evocaram a ausência de condições adequadas para o exercício do cuidado. Uma delas esclarece: "uai, minha casa é muito pequena. (...) não dá pra ele ir ao banheiro pra tomar um banho. Põe na cadeira de rodas ali dentro da sala, ali nós damos o banho nele. Põe água num balde, jogando assim com um copo d'água" (Entrevistada 3, 73 anos). Há referências à falta de orientação sobre a forma de cuidar: "ninguém nunca me deu conselho. Eu cuido lá mesmo do meu jeito” (Entrevistada 7, 57 anos).

A procura por ajuda profissional médica aparece em todos os casos. Todos os homens tomam medicamentos. Uma mulher explica: “ $a$ gente dá uns remédios também que ele 'acalma'. Agora tô achando que os remédio dele, parece que vai indo acostuma, né?" (Entrevistada 4, 73 anos). De maneira geral, as cuidadoras atribuem ao SUS uma ajuda irregular, de qualidade inferior e têm dificuldade em reconhecer o seu valor. Uma esposa diz: "lá [no Posto de Saúde] só tem remédio barato" (Entrevistada 1, 72 anos). Outra completa: "ambulância um dia ia, falhava duas semanas sem ir" (Entrevistada 5, 74 anos). Nenhuma das entrevistadas conseguiu acesso à reabilitação no sistema público. Uma única cuidadora relatou uso recomendado de órteses: "o médico receitou uma bengala e passou pra ele a fisioterapia, (...) pegou os aparelhos da perna que põem os pés de jeito, (...) e pegou uma tala, pra pôr no braço" (Entrevistada 5, 74 anos). Mesmo aquelas que se referem ao PSF relatam dificuldades para aceitar a ajuda externa. Uma delas explica: "eles até que me ofereceram, mas eu falei: 'não, não precisa de vim, não'. Eles vivem ocupados também, né? Eu faço. Eu dou muito conta de fazer. Aí eu fazia os curativos em casa" (Entrevistada 1, 72 anos).

O uso de calmantes - e a indicação médica para utilizá-los - é relatado por algumas cuidadoras; há as que escolhem tomar e as que preferem não tomar. Uma delas relata "o Rivotril consola a gente. Consola [risos]. (...) Que se a gente não tomar um calmante, não vai não [risos]" (Entrevistada 8, 67 anos), outra discorda "eles receitavam calmante pra mim e eu não tomo porque no outro dia eu não agüento fazer as coisas. Fico muito bamba, naquela moleza, uma fraqueza e eu não tomo, e eu não durmo bem, não [chora]" (Entrevistada 3, 74 anos). Por um lado o uso de calmantes é visto como ameaça à realização do cuidado efetivo. Por outro, a sim- 
ples expressão de emoções também é sentida como ameaça e precisa ser contida. "Tem dia que eu sou nervosa até comigo mesma. Mas com ele, não. Se a gente fizer raiva nele, ele volta o derrame. Uma vez eu assim, eu não dou demonstração, sabe? Porque é, se ele ficar pior do que está, fica pior pra mim, né?" (Entrevistada 8, 67 anos).

Muitas vezes é para Deus que elas apelam. Deus aparece em quase todas as entrevistas como força, refúgio, esperança e guardião do compromisso de cuidar. “Ah, eu peço a Deus pra me dar força e paciência. Às vezes eu entro pro quarto, choro um pouquinho, aí parece que aquilo desaparece um pouco, parece que Deus me dá força e eu... [chora]. Não é fácil a vida. Mas eu penso: 'tudo posso n'aquele que me fortalece', né? Quando eu tô triste, tô fraca, sentindo desamparada, eu peço a Deus, Ele me dá força, parece que na hora aquilo desaparece $e$, ó" (Entrevistada 3, 73 anos). Para muitas, o cuidado presente e passado é visto como desígnio de Deus: "uai, minha filha, o que vier, eu confio em Deus, né? Que eu acho que Deus não dá nada pra gente, que a gente não agüenta, você acha? Se Deus deu é porque a gente agüenta, né?" (Entrevistada 6, 77 anos). Elas confiam em um Deus que ajudará a suportar o momento atual e esperam d'Ele a graça de que a condição não se agrave: "ah, eu espero de Deus ter dó da gente, pra não piorar muito não [risos]" (Entrevistada 9, 73 anos). A mais velha das cuidadoras (Entrevistada 10), aos 90 anos, sente-se conformada: "eu conformo com a vontade de Deus. O quê que se há de fazer? Eu não posso judiar dele. (...) Tem de aceitar". Contudo, reconhece: "eu me sinto com força, mas de vez em quando a gente assim parece que vai desanimando, né? Porque vai ficando cada vez mais velha, mais sem força. Porque Ele dá a vida e tira a força, né? (...) Se eu acho difícil? Tem dia que a gente tá mais desanimada que eu acho difícil, mas depois não. Tudo é por Deus, vamos aceitar". O cuidado exercido, hoje, serve como esperança de um reconhecimento desse sacrifício em prol do marido e de uma recompensa divina futura, como é dito por estas duas esposas: "então hoje pra eu largar dele, hoje eu não largo não. Nem... vou fazer duas festas: uma aqui na Terra, outra lá no céu. Se Deus quiser [risos]" (Entrevistada 1, 72 anos); "Deus dá força pra gente. Que tem um ditado: 'quem planta colhe"' (Entrevistada 9, 73 anos).

A maioria das entrevistadas "entrega para Deus" suas súplicas, crises e silêncios. Isso é consistente com um estudo que utilizou grupos focais para entender as preces de idosos e que concluiu que, à medida que envelhece, a pessoa gradualmente desloca-se de estratégias de enfrentamento mais ativas para outras mais passivas 45. Essa "passividade" está associada com desfechos negativos, incluindo maior sofrimento psicológico. Por outro lado, Krause et al. 45 argumentam que isso poderia significar uma fé amadurecida que consegue: (a) diferenciar aquilo que se pode mudar do que não é possível modificar; (b) concentrar esforços em situações que podem ser modificadas; e (c) desprender-se emocionalmente daqueles aspectos de um problema fora de seu controle, focalizando-se na certeza de que, no fim, Deus assegurará o melhor desfecho possível. Desse modo, a religiosidade das esposas bambuienses revela certo fatalismo diante da situação que não admite alternativa, além daquela que é prosseguir cuidando "como e até quando Deus quiser”. Essa crença religiosa tampona sofrimentos individuais, mas também colabora para minimizar a responsabilidade social pelo cuidado e esconde a descrença nos aparelhos públicos existentes.

Fica a impressão de que estão ambos esquecidos, cuidador e quem precisa de cuidados, vivendo entre quatro paredes e, a seu modo, vivenciando a dura realidade da incapacidade funcional numa sociedade que não parece acreditar que está envelhecendo, não cria aparelhos para fazer face ao desafio que representa cuidar de idosos que não envelheceram com saúde.

A continuar dessa maneira, elas brevemente estarão duplamente desassistidas: não encontram, no âmbito familiar, pessoas que possam assumir ou dividir o cuidado dos maridos e serão elas as próximas a precisar de alguém que cuide delas.

De regra, as cuidadoras dizem que não é difícil cuidar do marido. Apenas uma delas admitiu dificuldades: "ah, eu enfraqueci muito. Olhando uma pessoa assim doente assim, sozinha. Eu não era magra assim, não. Eu era gordinha, bonitinha" (Entrevistada 1, 72 anos). Para as demais, as dificuldades são explicadas pelo seu próprio envelhecimento ou pela sua condição de saúde. Vários são os problemas de saúde apontados, e os sintomas podem ser físicos e/ou psicológicos. "Sou desanimada demais. Eu tenho problema nos pés. (...) Eu tenho depressão, eu tomo 'fluoxetina' direto" (Entrevistada 6, 77 anos). Duas senhoras estiveram internadas, uma foi para a casa da vizinha e uma outra para a casa de uma tia. Esta última afirma: "igual o médico falou, eu já machuquei meus braços demais pra pelejar pra ele não machucar, pra ele não cair, né? (...) Uma vez eu machuquei tanto que tive que ir pra casa da minha tia, pra ela tomar conta de nós" (Entrevistada 5, 74 anos). 
Ainda que neguem explicitamente que seja difícil cuidar do marido e minimizem o impacto do papel de cuidadora em suas vidas, o relato de todas as entrevistadas demonstra o quão penoso pode ser o exercício cotidiano desse papel. Uma entrevistada explica: “às vezes, outro olha a gente e acha que a gente 'vive' satisfeita com a vida, né? Mas não, porque passa trabalho demais, mas a gente vê os trabalho dos outros, a gente conforma, também, né? Porque pensa não é só eu que passo. Igual, às vezes, eu penso pra quê eu fui fazer isso, pegar... essa, como diz, essa cruz, né? Aí, eu penso que vai levando... Até o dia que Deus quiser, né?" (Entrevistada 4,73 anos).

O conjunto de relatos deixa claro não só que a esposa deve cuidar, mas também que deve calar suas dores, angústias, medos. Queixar-se de cansaço, pedir ou aceitar ajuda, é negar-se a fazer o que lhe foi predestinado, o que não pode ser passado adiante nem compartilhado. A esposa que é respeitada e admirada não é a que admite os seus limites, mas aquela que cala seus sentimentos e emoções, que nega suas dores e que continua a cuidar do outro, por mais que para isso tenha que se sacrificar e abandonar o próprio cuidado. A ela não é permitido queixar-se. Ela deve continuar resignada, dar mostras de discrição e de devoção em relação ao marido - este sim, doente, frágil e merecedor de toda a dedicação. O relato de todas as esposas veicula um universo de valores e normas em que o silêncio precisa ser mantido em respeito ao que se chama "dever" de esposa.

Em razão disso, a narrativa de todas revela muitas contradições. Uma mulher expressa o prazer que sente em cuidar "do que é dela"; entretanto, fala de sua tristeza: "tenho prazer. Porque é meu mesmo, né? Eu tenho que aceitar. (...) Não gosto de clamar com ninguém. Porque ninguém é obrigado a suportar o mal do outro. Então, choro" (Entrevistada 10, 90 anos). Outras minimizam o ônus decorrente do cuidado; no entanto, percebe-se certo descontentamento: "agora até que não está muito difícil não. Não tem nada difícil não. Solidão como assim? É tem dia que eu fico assim contrariada. Principalmente os dias que tá armando chuva, sabe?" (Entrevistada 2, 59 anos). Uma delas diz que cuidar não interfere porque a vida nunca foi fácil: "ah, boba, a vida da gente, toda vida foi dificil, né? Porque vida de gente pobre é difícil, mas a gente vai levando, né? Porque toda a vida a gente tá acostumado com a trabalheira, né? Sempre é a rotina" (Entrevistada 9, 73 anos). Outra se atrapalha na avaliação do que representa o cuidado em sua vida, insistindo que o importante é o marido ainda estar vivo: “mas agora tá mais fácil, né? (...) Era mais difícil, agora tá mais... Mas eu já tive um tempo mais fácil pra mim com ele. Agora tá mais difícil, mas já teve mais ainda, sabe? Agora já tá mais ou menos. Mas já passei trabalho, já valeu, mas sabe que ainda agradeço a Deus de eu inda ter ele comigo. Porque muitos que já ajudou a carregar ele, quantos já morreram e ele tá aî" (Entrevistada 5, 74 anos). Essas mulheres aprenderam desde crianças que ser esposa é um papel integral, que exige discrição, abnegação, resignação. Admitir a ajuda de um terceiro significa falhar na integralidade e permitir um intruso na intimidade da casa. Outra ponderação é que o cuidado é diário e esse terceiro, por vezes, não se dispõe a estar lá todos os dias. Para que alguém, de vez em quando, se o que vivo é rotina de todos os dias? Outro risco a não ser corrido é o de pedir e não obter a ajuda. Fontes irregulares de ajuda não são confiáveis (os profissionais de saúde do PSF, por exemplo). Por isso também, será Deus - aquele que nunca falta quem sempre é lembrado como único refúgio.

\section{Cuidar de um marido idoso em Bambuí}

A análise do conjunto de entrevistas revela que as mulheres de Bambuí cuidam de seus maridos idosos de uma forma integral, cotidiana, intuitiva, improvisada e solitária. Todas prestam cuidados ao idoso dependente, sem orientação de profissionais e com grande carência de recursos públicos e sociais de suporte. Para cuidar, elas lançam mão de estratégias de ordem material, institucional (ajuda profissional e da comunidade), psicológica e mística. As exigências concretas desse cuidado integral também interagem com a condição de saúde do marido e suas conseqüências em termos de incapacidade funcional e de dependência; com as características de quem é cuidado, com as limitações de quem cuida - ditadas pelos processos paralelos de envelhecimento e adoecimento da cuidadora -, com situações de penúria social, experimentadas ao longo de toda a vida, e com a ausência de suporte institucional e de aparelhos públicos que pudessem facilitar o cuidado no domicílio. Tudo isso permeia as dificuldades no cuidado cotidiano e colabora para aumentar o fardo das cuidadoras, bem como para prejudicar a efetividade das ações que elas realizam com o propósito de cuidar bem. Mesmo assim, elas tiveram grande dificuldade em admitir que o cuidado signifique um fardo em suas vidas. No relato das mulheres de Bambuí, a experiência de cuidar do marido reflete 
mais um senso de obrigação que de realização pessoal, mais uma sina do que uma escolha.

Diversos estudos demonstram que a carga de cuidado dos idosos dependentes recai desproporcionalmente sobre as mulheres $35,37,38$, 39,42. Apesar disso, elas raramente reconhecem muitas das tarefas que realizam como "cuidado per si”, já que envolvem trabalhos que elas realizaram ao longo de toda a vida (preparar a comida, fazer a faxina, lavar roupas) 46 . Isso foi corroborado neste estudo. Em Bambuí, todas as cuidadoras entrevistadas vêem com naturalidade o fato de serem elas a cuidar de seus maridos, não questionam nem esperam que outros se ofereçam para compartilhar o cuidado. A maioria não soube precisar quando começou a cuidar do marido. A cultura lhes informa que o cuidado é indissociável das tarefas de uma esposa.

A tendência a minorar ou, mesmo, a negar o fardo inerente ao exercício do cuidado que marca todas as narrativas nos remete fortemente à cultura que define, de maneira específica, o papel, as responsabilidades e as obrigações da mulher e estabelece que cuidar de um idoso dependente é uma obrigação "natural" da esposa. Ela nos remete também a um conjunto de regras que regem as relações conjugais e de gênero na sociedade bambuiense, bem como a um universo religioso que sanciona regras sociais e modelos de comportamento e promete recompensar no futuro, em uma vida eterna e melhor.

Os estudos têm repetidamente revelado que cuidadores experimentam altos níveis de estresse, fadiga 38,41 e que a saúde do cuidador sofre 37 , havendo um maior risco de morbidade psiquiátrica e física quando comparados à população geral e a grupos-controle 21,22,47,48. Em Bambuí, todas as entrevistadas referiramse à piora do estado de saúde e uso crônico de medicamentos, inclusive antidepressivos, hipnóticos e ansiolíticos. Todavia, elas não relacionam cuidado e agravamento da condição de saúde. Essa síntese causal mais uma vez não ocorre no discurso da maioria delas. Além disso, o cuidado com a própria saúde é negligenciado em prol do cuidado do idoso, na ilusão de que tal sacrifício possa ajudar - ao marido e a si mesma, em resposta à demanda por um cuidado integral e intransferível.

Ward-Griffin \& Marshall 19 discutem as mudanças na provisão de cuidados para pessoas idosas frágeis ou incapacitadas. Segundo esses autores, desde os anos 50, nos países industrializados, existe uma rede de seguridade social e um sistema formal de cuidado destinado a idosos com necessidades especiais. Na última dé- cada, esses países assistiram à retração das provisões estatais e a um retorno para a era de bemestar primitivo, no qual o cuidado de longa permanência ao idoso é transferido para a família, mesmo para aquela população mais cronicamente incapacitada. Atualmente, no Canadá, por exemplo, cerca de $90,0 \%$ do cuidado domiciliário de idosos, com uma complexidade crescente, é assumido por cuidadores familiares 49 .

Essa reflexão aumenta, ainda mais, a responsabilidade pela sistematização do cuidado domiciliário no nosso meio. Se os países com maiores recursos e com uma rede de seguridade social mais bem estruturada concluem que é necessário dar suporte à família para que ela cuide do idoso dependente, que dizer da nossa realidade em que essa preocupação nunca existiu? Em um estudo com famílias de baixa renda que prestavam cuidados a adultos com perda de independência no Município de São Paulo, Brasil, de 1991 a 1995, mais de $90,0 \%$ das famílias não recebiam ajuda de serviços, organizações ou grupos voluntários e/ou agências particulares; porém, cerca de $30,0 \%$ delas confirmaram que, se pudessem receber tal auxílio, ficariam satisfeitas 25. Caso o cuidado ao idoso dependente continue sendo entendido como um cuidado a ser realizado pela mulher, é importante que se estabeleçam políticas públicas de assistência domiciliária, com redução do ônus do cuidado, com perspectivas de reabilitação funcional e com maior orientação para as atividades rotineiras.

Finalmente, cabe ressaltar que a pessoa que cuida de idosos nem sempre escolheu ser cuidador. A necessidade de cuidar de um idoso decorre de uma imposição circunstancial mais do que de uma escolha. A figura do cuidador informal emerge de relações familiares, quase sempre fragilizadas pela presença da doença e pelo que foi vivenciado, exigindo severos e profundos "arranjos” na organização e dinâmica intrafamiliares para corresponder às necessidades da pessoa dependente. Comumente esses cuidadores não contam com conhecimentos prévios e básicos para o desempenho de seu papel, em consonância com as necessidades do idoso funcionalmente dependente, muitas vezes por períodos prolongados. Essa é a realidade que assegura que idosos dependentes continuem vivos. Essa realidade exige reconhecimento por parte dos órgãos públicos de saúde, assistência social e esforços intersetoriais devem ser feitos para proporcionar um cuidado adequado a idosos dependentes e às pessoas que cuidam deles. 


\section{Resumo}

O presente trabalho tem por objetivo investigar as características do processo de cuidar e a experiência de mulheres que cuidam de seus maridos idosos em Bambuí, Minas Gerais, Brasil. Entre os participantes do Projeto Bambuí, selecionaram-se dez idosos que necessitavam de cuidador e disseram ser cuidados por suas esposas. As dez esposas foram entrevistadas, utilizando-se de um roteiro de questões, com os grandes eixos temáticos sugeridos pela literatura. A análise dos dados inspirou-se na corrente interpretativa da antropologia e nos remete a uma cultura que define o papel, as responsabilidades e as obrigações da mulher, determina as regras que regem as relações conjugais, dita normas e modelos de comportamento e estabelece que cuidar de um idoso dependente é uma obrigação "natural" da mulher. Apesar de todas as evidências, as mulheres têm dificuldade em dissociar o cuidado de seu papel de esposas e em admitir o fardo. Cuidador e necessitados de cuidados vivem a dura realidade da incapacidade funcional, de modo integral, intuitivo e improvisado. Essa reflexão reforça a responsabilidade pela sistematização do cuidado domiciliário no nosso meio.

Antropologia; Idoso; Cuidadores

\section{Colaboradores}

K. C. Giacomin participou do delineamento do estudo, realizou e transcreveu todas as entrevistas, desenvolveu a análise dos dados e foi a redatora principal do artigo. E. Uchôa orientou o delineamento do estudo, a discussão e análise dos resultados e a revisão crítica final do artigo. M. F. F. Lima-Costa participou da discussão do delineamento do estudo e da redação final do trabalho.

\section{Referências}

1. Instituto Brasileiro de Geografia e Estatística. Censo demográfico, 2000. Rio de Janeiro: Instituto Brasileiro de Geografia e Estatística; 2002.

2. Russel R. In sickness and in health: a qualitative study of elderly men who care for wives with dementia. J Aging Stud 2001; 15:351-67.

3. Lima-Costa MF, Barreto S, Giatti L, Uchoa E. Desigualdade social e saúde entre idosos brasileiros: um estudo baseado na Pesquisa Nacional por Amostra de Domicílios. Cad Saúde Pública 2003; 19:745-57.

4. Lima-Costa MF, Barreto SM, Giatti L. Condições de saúde, capacidade funcional, uso de serviços de saúde e gastos com medicamentos da população idosa brasileira: um estudo descritivo baseado na Pesquisa Nacional por Amostra de Domicílios. Cad Saúde Pública 2003; 19:735-43.

5. Caldas CP. Envelhecimento com dependência: responsabilidades e demandas da família. Cad Saúde Pública 2003; 19:773-81.

6. Lima-Costa MF, Veras R. Saúde pública e envelhecimento. Cad Saúde Pública 2003; 19:700-1.

7. Ramos LR. Epidemiologia do envelhecimento. In: Freitas EV, Py L, Néri AL, Gorzoni ML, Rocha SM, organizadores. Tratado de geriatria e gerontologia. Rio de Janeiro: Guanabara Koogan; 2002. p. 72-8.

8. Uchôa E, Firmo JOA, Lima-Costa MF. Envelhecimento e saúde: experiência e construção cultural. In: Minayo MCS, Coimbra Jr. CEA, organizadores. Antropologia, saúde e envelhecimento. Rio de Janeiro: Editora Fiocruz; 2002. p. 25-50.

9. Guerra HL, Vidigall PG, Lima-Costa MF. Biomedical factors associated with hospitalization of older adults: The Bambuí Health and Aging Study (BHAS). Cad Saúde Pública 2003; 19:829-38.

10. Lima-Costa MF, Guerra HL, Barreto SM, Guimarães RM. Diagnóstico da situação de saúde da população idosa brasileira: um estudo da mortalidade e das internações hospitalares públicas. Inf Epidemiol SUS 2000; 9:23-41.

11. Instituto Brasileiro de Geografia e Estatística. PNAD (Pesquisa Nacional por Amostra de Domicílio) acesso e utilização de serviços de saúde 1998. Rio de Janeiro: Instituto Brasileiro de Geografia e Estatística; 2000.

12. Rosa TEC, Benício MHA, Latorre MRDO, Ramos LR. Fatores determinantes da capacidade funcional entre idosos. Rev Saúde Pública 2003; 37:40-8.

13. Stuck AE, Walthert JM, Nikolaus T, Büla CJ, Hohmann C, Beck JC. Risk factor for functional status decline in community-living elderly people: a systematic literature review. Soc Sci Med 1999; 48:445-69.

14. Gill TM, Williams CS, Richardson ED, Berkman LF, Tinetti ME. A preditive model for ADL dependence in community-living older adults based on a reduced set of cognitive status items. J Am Geriatr Soc 1997; 45:441-5.

15. Agree EM. The influence of personal care and assistive devices on the measurement of disability. Soc Sci Med 1999; 48:427-43.

16. Hébert R. La perte d'autonomie. Neurologie, Psychiatrie, Gériatrie 2003; 3:33-40. 
17. Néri AL, organizador. Cuidar de idosos no contexto da família: questões psicológicas e sociais. São Paulo: Alínea; 2002.

18. Grundy E. The epidemiology of aging. In: Tallis RC, Fillit HM, editors. Brocklehurst's textbook of geriatric medicine and gerontology. London: Churchill Livingstone; 1998. p. 1-18.

19. Ward-Griffin C, Marshall VW. Reconceptualizing the relationship between "public" and "private" eldercare. J Aging Stud 2003; 17:189-208.

20. Brasil. Portaria do Gabinete do Ministro de Estado da Saúde de n. 1.395, de 9 de dezembro de 1999, que aprova a política nacional de saúde do idoso e dá outras providências. Brasília: Diário Oficial da União 1999; 13 dez.

21. Ducharme F. La chaire de recherche en soins infirmiers à la personne âgée et à la famille: un programme visant à soutenir les familles par le développement d'approches de soins novatrices. La Gérontoise 2002; 13:13-6.

22. Canadian Study on Health and Aging. Patterns of caring for people with dementia in Canada. Can J Aging 1994; 13:470-87.

23. Caldas CP. O idoso em processo de demência: o impacto na família. In: Minayo MCS, Coimbra Jr. CEA, organizadores. Antropologia, saúde e envelhecimento. Rio de Janeiro: Editora Fiocruz; 2002. p. 51-71.

24. Santos SMA, Dalgalarrondo P. Familiarizando-se com o estranho e transpondo as barreiras culturais. Jornal Brasileiro de Neuropsiquiatria Geriátrica 2001; 2:74-8.

25. Karsh UMS, organizador. Envelhecimento com dependência: revelando cuidadores. São Paulo: EDUC; 1998.

26. Giacomin KC. Projeto Bambuí: um estudo de base populacional da prevalência e dos fatores associados à necessidade de cuidador entre idosos [Dissertação de Mestrado]. Belo Horizonte: Faculdade de Medicina, Universidade Federal de Minas Gerais; 2004.

27. Meyerhoff B, Simic A, editors. Life's career aging. Cultural variations on growing old. London: Sage Publications; 1978.

28. Corin E. Régards anthropologiques sur la veillesse. Anthropol Soc 1982; 6:63-90.

29. Minayo MCS, Coimbra Jr. CEA. Entre a liberdade e a dependência: reflexões sobre o fenômeno social do envelhecimento. In: Minayo MCS, Coimbra Jr. CEA, organizadores. Antropologia, saúde e envelhecimento. Rio de Janeiro: Editora Fiocruz 2002; p. 11-24.

30. Geertz C. The interpretation of cultures. New York: Basic Books Inc. Publishers; 1973.

31. Uchôa E. Espace dévolu, espace désiré, espace révendiqué. Indifférenciation et folie d'Ajaratou. Anthropol Soc 1993; 17:157-72.

32. Uchôa E, Vidal JM. Antropologia médica: elementos conceituais e metodológicos para uma abordagem da saúde e da doença. Cad Saúde Pública 1994; 10:497-504.

33. Uchôa E. Epidemiologia e antropologia: contribuições dos aspectos transculturais da depressão. In: Canesqui AM, organizador. Ciências sociais e saúde. São Paulo: Editora Hucitec/Rio de Janeiro: ABRASCO; 1997. p. 87-109.
34. Lima-Costa MF, Uchôa E, Guerra HL, Firmo JOA, Vidigal PG, Barreto SM. The Bambuí Health and Aging Study (BHAS): methodological approach and preliminary results of a population-based cohort study of the elderly in Brazil. Rev Saúde Pública 2000; 34:126-35.

35. Ducharme F, Trudeau D. Qualitative evaluation of a stress management intervention for elderly caregivers at home: a constructivist approach. Issues Ment Health Nurs 2002; 23:691-713.

36. Sörensen S, Pinquart M, Duberstein P. How effective are interventions with caregivers? An updated meta-analysis. Gerontologist 2002; 42:356-72.

37. Brewer L. Gender socialization and the cultural construction of elder caregivers. J Aging Stud 2001; 15:217-35.

38. Bédard M, Pedlar D, Martin NJ, Malott O, Stones MJ. Burden in caregivers of cognitively impaired older adults living in community: methodological issues and determinants. Int Psychogeriatr 2000; $12: 307-32$.

39. Bédard M, Molloy DW, Squire L, Dubois S, Lever JA, O'Donnell M. The Zarit Burden Interview: a new short version and screening version. Gerontologist 2001; 41:652-7.

40. Noonan AE, Tennstedt SL, Rebelsky F. Making the best of it: themes of meaning among informal caregivers to the elderly. J Aging Stud 1996; 10: 313-27.

41. Pearlin LI, Mullan JT, Semple SJ, Skaff MM. Caregiving and the stress process: an overview of concepts and their measures. Gerontologist 1990; 30:583-94.

42. Zarit SH, Todd PA, Zarit JM. Relatives of the impaired elderly: correlates of feelings of burden. Gerontologist 1980; 20:649-55.

43. Minayo MCS, organizador. Pesquisa social: teoria, método e criatividade. São Paulo: Editora Hucitec/Rio de Janeiro: ABRASCO; 1998.

44. Minayo MCS. Introdução à metodologia de pesquisa social. In: Minayo MCS, organizador. O desafio do conhecimento: pesquisa qualitativa em saúde. São Paulo: Editora Hucitec/Rio de Janeiro: ABRASCO; 1993. p. 19-89.

45. Krause N, Chatters LM, Meltzer T, Morgan DL. Using focus groups to explore the nature of prayer in late life. J Aging Stud 2000; 14:191-212.

46. Dwer J, Coward. Gender, families and elder care. Newbury Park: Sage Publications; 1992.

47. Williamson GM, Schulz R. Coping with specific stressors in Alzheimer's disease caregiving. Gerontologist 1993; 33:747-55.

48. Kruse A. Caregivers coping with chronic disease, dying and death of an aged family member. Rev Clin Gerontol 1991; 1:411-5.

49. Ducharme F, Perodeau G, Trudeau D. Perceptions, strategies adaptatives et attentes des femmes âgées aidantes familiales dans la perspective du virage ambulatoire. Can J Ment Health 2000; 19:79-103.

Recebido em 28/Jul/2004

Versão final reapresentada em 18/Mar/2005

Aprovado em 01/Abr/2005 